
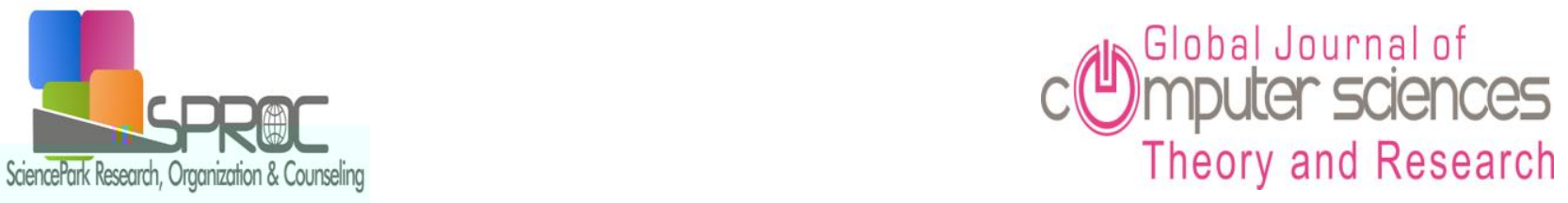

www.gjcs.eu

\title{
Effectiveness measurement of spectral clustering algorithm
}

Farag Homed Ali Kuwil*,

Suggested Citation:

Abstract 
1. Introduction

2. Overview of Potential Fields

- $\rightarrow$ A F

- $\rightarrow \mathrm{M} \quad \mathrm{F}$

- $(-, \rightarrow E \quad S \quad F$

- $(\rightarrow E$ S $\quad F$

- ( ) $\mathbf{I} \quad \mathrm{S} \quad \mathrm{F}$ 


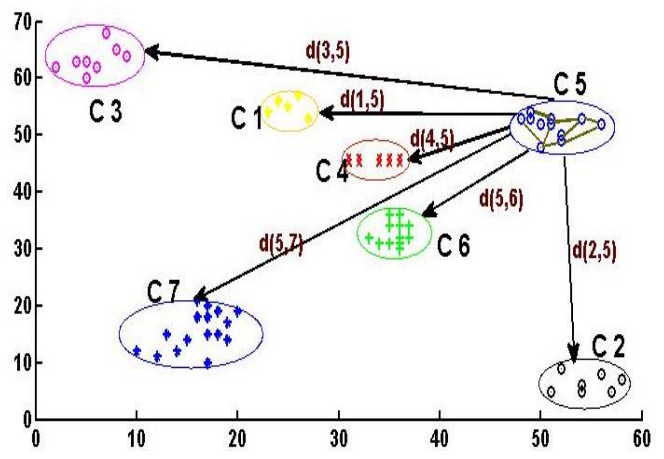

3. Algorithm Analysis

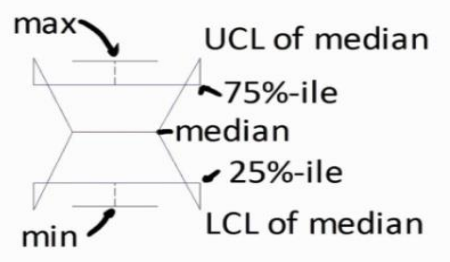


- Max

- Min

- Range

- Median

- 25\%-ile (Q1)

- 75\%-ile (Q3)

- Upper Confidence Limit (UCL)

- Lower Confidence Limit (LCL)

- IQR 


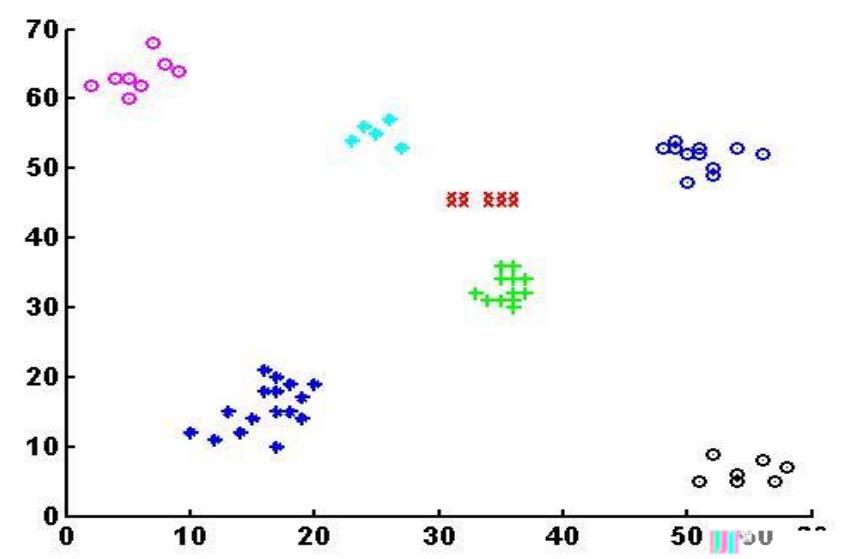

$\operatorname{ESF}_{1}, \mathrm{ESF}_{1}, \quad \mathrm{ISF}_{\mathbf{1}}$

$\operatorname{ISF}_{(\mathrm{c.1})}$

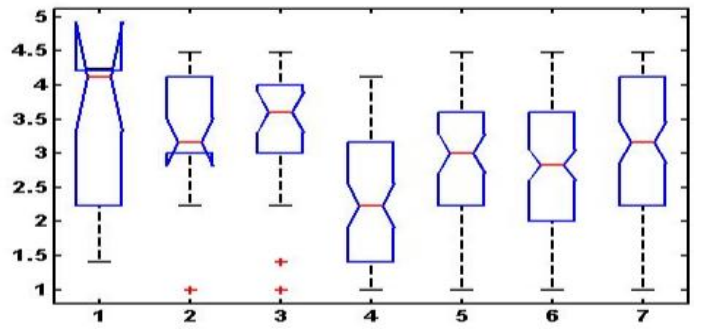

$\mathrm{C}_{(1)}$

$C_{(2)}$

$C_{(2)} C_{(3)}$ 
$\mathrm{ESF}_{\text {(c.k ) }}$
A.F

M.F

$\operatorname{ISF}_{(\mathrm{c.k})} \mathrm{C}_{(1)} \quad \mathrm{C}_{(5)}$

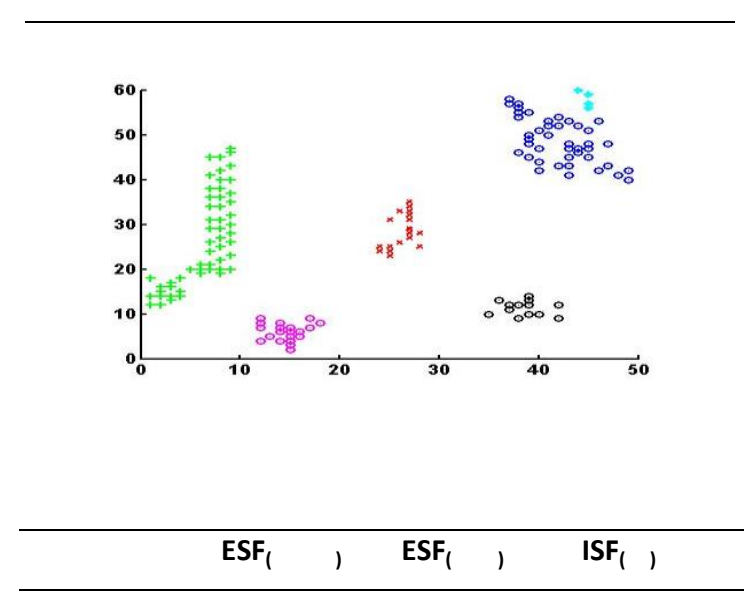




\begin{tabular}{|c|c|c|c|c|c|}
\hline$c_{(1)} \quad c_{(2)}$ & $c_{(3)}$ & & & & $C_{(4)}$ \\
\hline & $\mathrm{ESF}_{1}$ & 1 & $\mathrm{ESF}_{1}$ & 1 & $\mathrm{ISF}_{(}$, \\
\hline
\end{tabular}

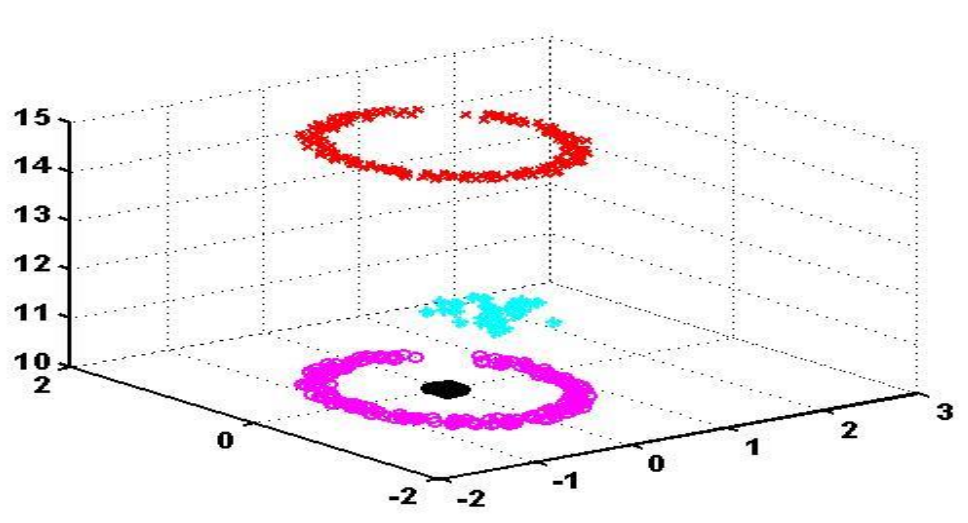

A.F

$\operatorname{ISF}_{(.5)}$

$E F_{1}, c_{(2)} \quad c_{(5)}$ 


\begin{tabular}{lllll}
\hline $\operatorname{ESF}_{1}$, & $\mathrm{ESF}_{\mathbf{1}}$, & $\mathrm{ISF}_{\mathbf{1}}$, \\
\hline
\end{tabular}
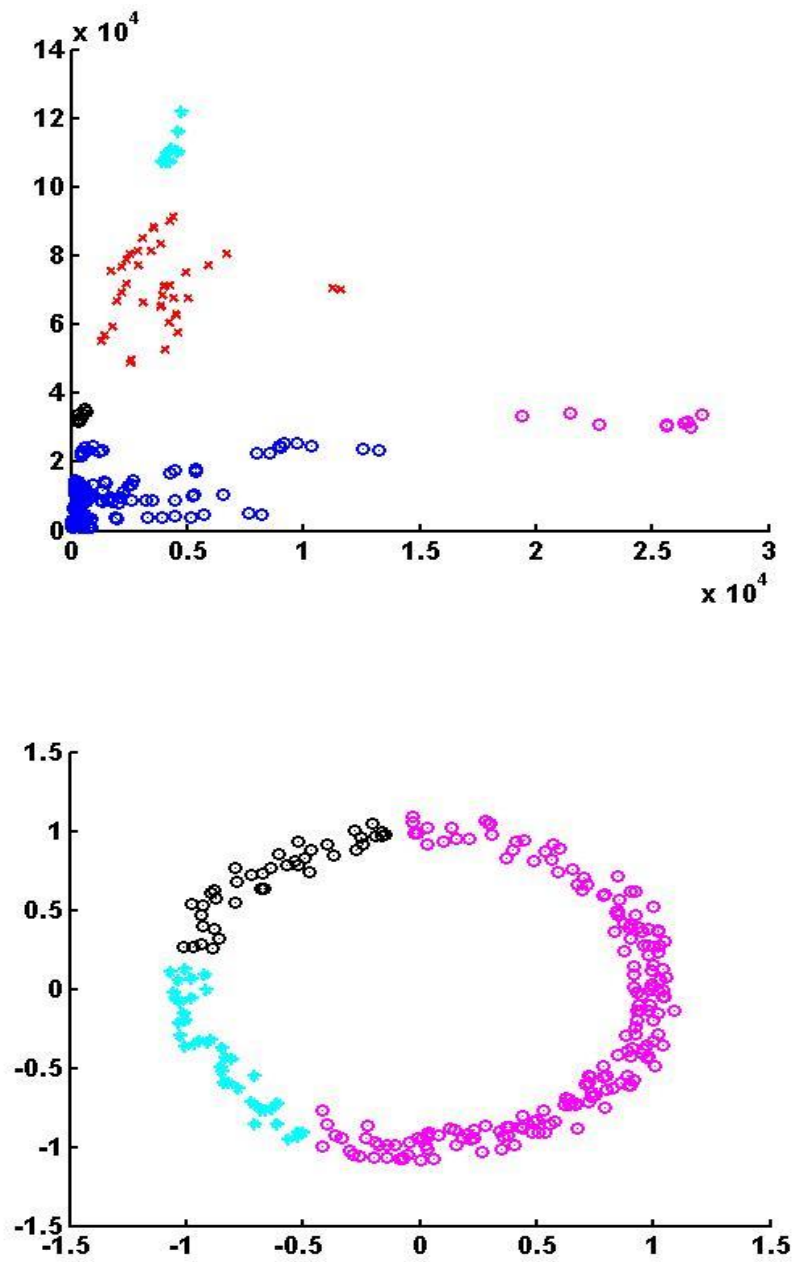
A.F

M.F

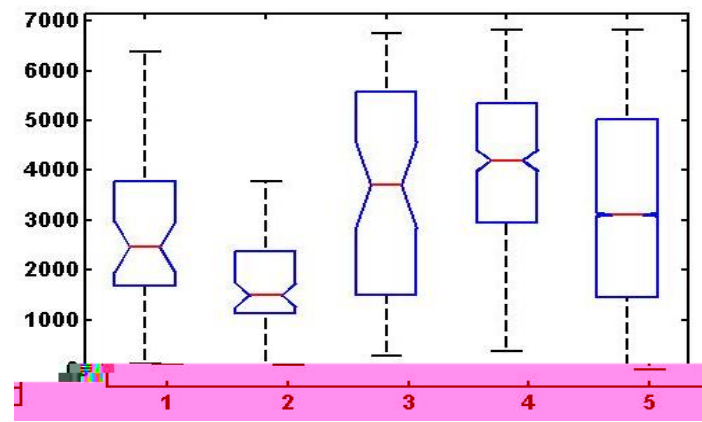

$\mathrm{ESF}_{1}, \mathrm{ESF}_{1}, \mathrm{ISF}_{\mathbf{1}}$,

5. Discussion 
M.F

A.F

A.F M.F

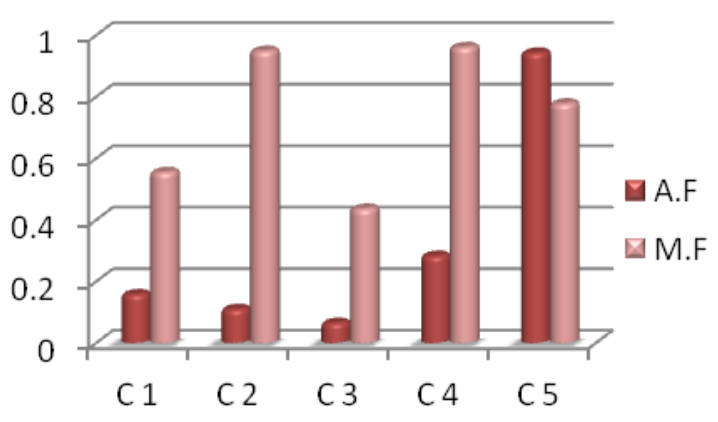


6. Conclusion and Future Work

References

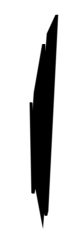

$N$

$N$ 